\title{
Bursa Bölgesinde Kullanılan Damla Sulama Sistemlerinin Performansları
}

\author{
Bayram DAVARCI ${ }^{1}$ (D) ismail TAŞ ${ }^{* 2}$ \\ ${ }^{1}$ Bursa Gıda ve Yem Kontrol Merkez Araştırma Enstitüsü Müdürlüğ̈̈, Osmangazi, Bursa \\ ${ }^{2}$ Çanakkale Onsekiz Mart Üniversitesi, Ziraat Fakültesi, Tarımsal Yapılar ve Sulama Bölümü, Terzioğlu \\ Yerleşkesi, Çanakkale
}

Öz: Tarımsal üretimin en önemli parametresi olan suyun, tasarruflu bir şekilde kullanılması hem su kaynaklarının korunmasını, hem de fazla sulamadan kaynaklanacak çevre sorunlarının bertaraf edilmesine katkı sağlar. Damla sulama yöntemi bu açıdan istenilen faydaları sağlayabilecek bir sulama yöntemidir. Sistemin tasarım ve projelendirme aşamalarında, kurulumun yapılacağı arazi için gerekli testlerin ve ölçümlerin yapılması çok önemlidir. Ayrıca, sisteme uygun işletme biçimlerinin de belirlenip kullanıcıya benimsetilmesi diğer bir önemli husustur. Mevcut durumda sistemlerin büyük bölümü belirtilen şekilde kurulmadığı için her açıdan beklenilen katkıları, tasarrufları ve kolaylıkları sağlayamamaktadır. Bu çalışmada, Bursa ili sınırlarında meyve bahçelerinde kullanılmakta olan damla sulama sistemlerinin performansı incelenmiştir. Test edilen manifoldların Damlatıcı Debi Türdeşliği (EU) değerleri \%60-89 arasında değişmiş olup, sadece 10 tane işletmenin EU değeri iyi sınıfta (\%80 -89) yer almıştır. Dağılım Türdeşliği (DU) değerleri, \%71-94, Türdeşlik Katsayısı (UC) değerleri \% 81-97, i̇statistiksel Eş Dağııı (Us) değerleri ise \%68-96, Sistem Su Uygulama Randımanı (Ea) değerleri \%85-95 ve Alt Çeyrek Gerçek Potansiyel Uygulama Randımanı (PELQ) değerleri ise \%64-85 arasında değişim göstermiştir. Sonuçlar dikkate alındığında, test yapılan işletmelerin hem damla sulama sistemlerinde hem de bunların işletilmesinde ciddi problemlerle karşı karşıya oldukları söylenebilir.

Anahtar Kelimeler: damlatıcı debi türdeşliği, dağılım türdeşliği, türdeşlik katsayısı, istatistiksel eş dağılım

\section{Performance of Drip Irrigation Systems Used in Bursa Region}

\begin{abstract}
Economical use of water, which is the most important parameter of agricultural production, contributes to both the protection of water resources and the elimination of environmental. Drip irrigation method is an irrigation method that can provide exactly the desired benefits in this sense. It is very important to carry out the necessary tests and measurements for the land on which the installation will be made during the design and project stages of the system. In addition, it is another important issue to determine the appropriate operations for the system and adopt them to the user. Currently, since most of the systems are not installed as specified, they cannot provide expected contributions, savings and conveniences in every aspect. In this study, the performance of drip irrigation systems used in orchards of Bursa province was assessed. The dripper flow homogeneity (EU) values of the tested manifolds varied between 60-89\%, and only the EU value of 10 enterprises was classified as good (80-89\%). Distribution Coexistence (DU) values varied between 71-94\%, Coexistence Coefficient (UC) values between 81-97\%, Statistical Co-Distribution (Us) values between 68-96\%, System Water Application Efficiency (Ea) values between 85-95\% and Lower Quarter Actual Potential Application Efficiency (PELQ) values varied between 64-85\%. Considering the results, it can be said that there are serious problems in both the drip irrigation systems and their operation in the tested gardens.
\end{abstract}

Keywords: emission uniformity, distribution uniformity, uniformity coefficient, statistical uniformity

\section{GíRiş}

Canlı yaşamının sürdürülmesi için gerekli olan su, yalnızca ekonomik değil, kültürel ve sosyal açıdan da çok önemli bir doğal kaynaktır. Artan nüfus ile suya olan ihtiyaç giderek artmaktadır. Dolayısıyla suyu kullanan sektörler arasında su kullanımı açısından bir rekabet ve tasarruf etme ortamı oluşturmaktadır. Su kaynaklarının dengesiz dağılımı, suya olan ihtiyacın giderek artması, mevcut su kaynaklarının ihtiyacı karşılayamayacak duruma gelmesi, suyun randımanlı kullanılamaması gibi nedenler, önümüzdeki yıllarda suya olan baskının artması ve ihtiyaç duyulan besin gereksiniminin sağlanamaması gibi ciddi riskler yaratacaktır (Mohammed, 2018).

Bitkinin ihtiyaç duyduğu zamanda ve miktardaki su, bitki kök bölgesine iletilebilirse ancak o zaman üretimde artış ve kaliteli ürün elde edilebilir. Bunun için bölgenin topoğrafik yapısı, iklim özellikleri, su kaynaklarının durumu, sulama suyu ücretleri, arazinin drenaj koşulları, bölge çiftçisinin sulama alışkanlıkları, yetiştiriciliği yapılacak olan bitkinin özellikleri ve su istekleri bilinmesi gereken başlıca faktörlerdir.

Ülkemizdeki çiftçilerin büyük çoğunluğu aile büyüklerinden öğrendikleri şekliyle tarımsal üretim yapmakta olup, modern üretim tekniklerine geçiş istenilen seviyeye ulaştırılamamıştır. Çiftçiler, basınçlı sulama sistemlerini, sahip oldukları su kaynaklarının kalite ve kantinite özelliklerini, toprak özelliklerini ve topoğrafya durumunu hesaba katmadan basınçlı sulama sistemine geçmektedirler.

Sorumlu Yazar: tas ismail@yahoo.com. Bu çalışma yüksek lisans tez ürünüdür.

Geliş Tarihi: 12 Nisan 2019

Kabul Tarihi: 20 Nisan 2020 
Ancak sistemin randımanlı çalışabilmesi için kurulumdan önce yapılması gereken analizler yapılmaması, projelerin konunun uzmanı olmayan kişilerce yapılıp arazide uygulanması, doğru şekilde tasarlanmış kurulmuş sistemlerinden doğru şekilde işletilememesi gibi birçok nedenden dolayı, basınçlı sulama sistemlerinden beklenilen yararlar sağlanamamaktadır. Hatta çok büyük maliyetlerle kurulan sistemler işletilememelerinden dolayı bazı durumlarda sökülüp atılmaktadır.

Yeterli eğitim ve donanıma sahip olmayan kişiler tarafından damla sulama sistemlerinin projelendirilmesi ve kurulumunun yapılması, sistem tasarımının en başında dikkate alınması gereken suyun kimyasal özellikleri, toprak yapısı, topoğrafya koşulları ve yetiştirilmesi öngörülen bitkinin su isteğinin göz önüne alınmadan sistemin kurulması, sistemden istenilen performansın elde edilmesini engellemektedir (Yazgan ve ark., 2000).

Basınçlı sulama sistemlerinin tasarımında asıl gaye, proje alanında suyun iletilmesinin zor olduğu, sistemin son kısmına yakın bitkilere yeterli suyun iletilmesini sağlamaktır. Bunun hesaplaması sistemin üzerindeki damlatıcı debilerinden en düşük olanlarının \%25'inin debi değerlerinin genel debi değerleri ortalamasına oranlanması şeklinde ortaya konabilir (Keller ve Karmeli, 1975).

Orta (1991), Antalya bölgesinde yürüttüğü araştırmada, damla sulama sistemi kullanan 9 adet işletmenin mevcut durumlarını, yetiştirilen bitki, kullanılan suyun kalite kriterleri, toprak yapısı ve arazi şartlarını da göz önüne alarak yeniden projelendirdiğinde, daha önceden kurulmuş olan sistemin yukarıda bahsedilen kriterlere uygun olarak projelendirilmediğini, kullanılan suyun yeterince filtreleme yapılmadan sisteme verildiğini, bu sebepten damlatıcılarda tıkanmaların meydana geldiğini, diğer taraftan sistemi kullanan çiftçilerin damla sulama konusuna yeterince hakim olmadıklarını ve sistemde kullanılan bazı parçaların kalite normlarındaki eksikliklerden dolayı istenilen düzeyde randımanlı çalışmadıklarını belirlemiştir.

Çalışma kapsamında Bursa ilinin Osmangazi (11 adet), Mustafakemalpaşa (2 adet), Gürsu (1) ve İnegöl (1 adet) ilçelerinde en az iki manifolda sahip meyve bahçelerinde toplamda 15 işletmenin damla sulama sistem performansları incelenmiş ve performans gösterileri ile değerlendirilmiştir.

\section{MATERYAL VE YÖNTEM \\ Materyal}

Bursa $39^{\circ} 35^{\prime}$ ve $40^{\circ} 40^{\prime}$ doğu boylamları ile $28^{\circ} 10^{\prime}$ ve $30^{\circ}$ $00^{\prime}$ kuzey enlemleri arasında yer almaktadır (Şekil 1). Bursa

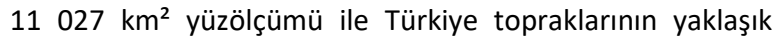
\%1.5'ine sahiptir. Bursa ili topraklarının \%17'lik kısmı ovalardan meydana gelmektedir. Bursa ili topraklarının 2 458685 hektarını kahverengi orman toprakları, 516272 hektarını kireçsiz kahverengi orman toprakları, 118255 hektarını alüvyol topraklar, 34088 hektarını kolüvyol topraklar ve 23436 hektarını vertisol topraklar meydana getirmektedir.

Çalışma yapılan ilçeler, Osmangazi 64288 ha yüzölçümüne, 17126 ha tarım alanına, Gürsu 11800 ha yüzölçümüne, 4 440 ha tarım alanına, İnegöl 101206 ha yüzölçümüne, 24 604 ha tarım alanına, Mustafakemalpaşa 172209 ha yüzölçümüne ve 52142 ha tarım alanına sahiptir. Bursa Karadeniz ve Akdeniz ikliminin geçiş kuşağında yer almaktadır. Bursa'da yıllık ortalama toplam yağış miktarı $706.9 \mathrm{~mm}$, yıllık ortalama sıcaklık $14.6{ }^{\circ} \mathrm{C}^{\prime}$ dir.

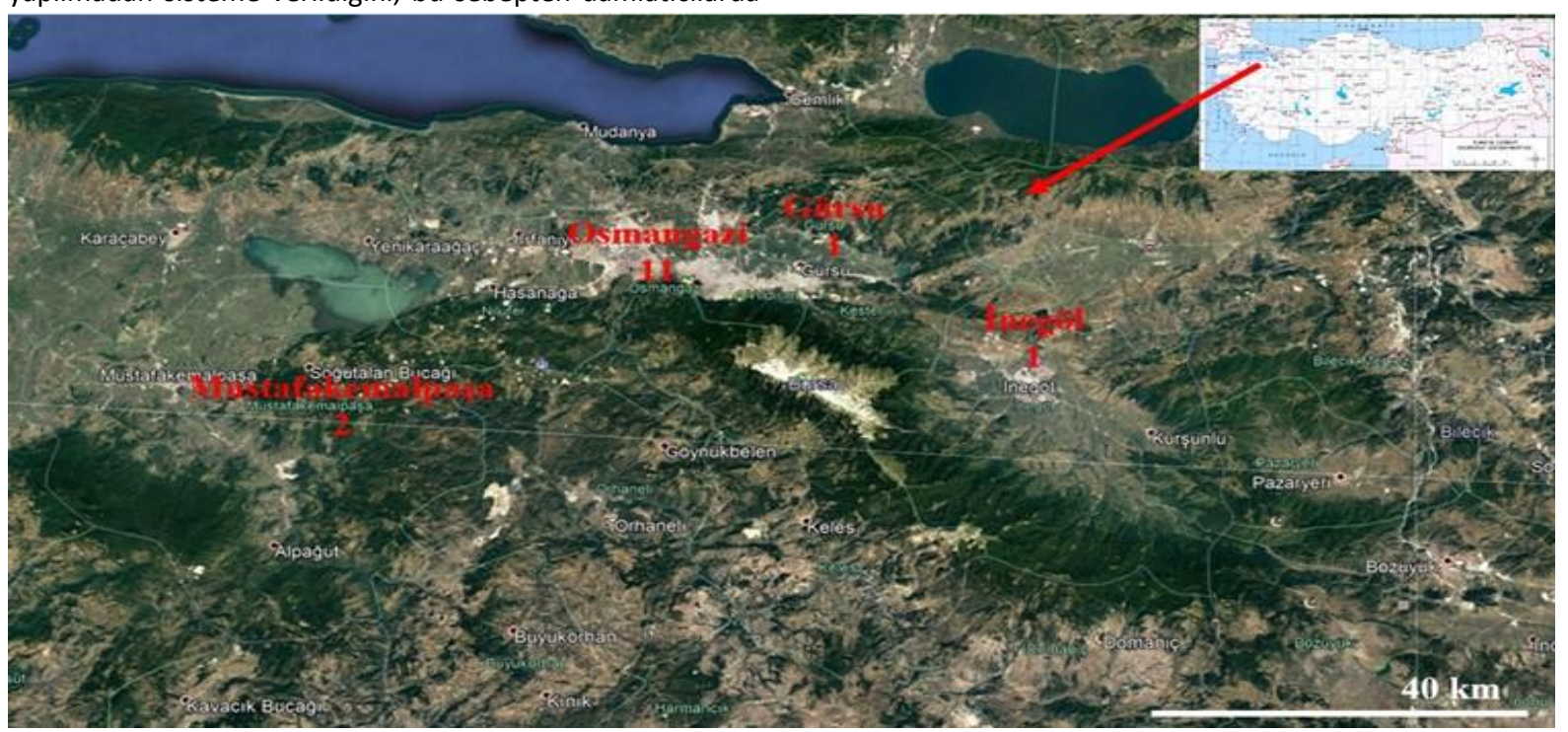

Şekil 1. Bursa ili haritası, test yapılan bölgeler ve test sayıları 


\section{Yöntem}

Araştırmanın yürütüldüğü işletmelerde manifold (yan boru) başındaki lateral, başlangıçtan 1/3'üncü mesafedeki lateral, 2/3'üncü mesafedeki lateral ve sondaki lateral üzerindeki ilk damlatıcılar, bundan $1 / 3$, orta, $2 / 3$ mesafedeki ve son damlatıcıların debileri 10'ar dakikalık sürelerle 3'er tekerrür şeklinde ölçümleri gerçekleştirilmiştir (Lamm ve ark., 1997).

Damlatıcı Debi Türdeşliği (EU)

Keller ve Karmeli (1975) tarafından verilen Eşitlik 1 ile hesaplanmıştır.

$E \mathrm{U}=\left[1-1.27 \frac{\mathrm{C}_{v}}{\mathrm{~N}^{0.5}}\right] \frac{\mathrm{q}_{\min }}{\overline{\mathrm{q}}}$

EU : Damlatıcı debi yayınım (çıkış) türdeşliği, (\%)

$\mathrm{N}$ : Değerlendirilen damlatıcı sayısı, (adet)

Cv : Varyasyon katsayısı

qmin : Minimum damlatıcı debisi, (l/h)

$\overline{\mathrm{q}} \quad$ : Ortalama damlatıcı debisi, L/h

Dağılım Türdeşliği (DU)

Merriam ve Keller, (1978) tarafından verilen Eşitlik 3 ile hesaplanmıştır.

$\mathrm{DU}=100\left(\frac{\mathrm{q}_{\min }}{\overline{\mathrm{q}}}\right)$

Eşitlikte;

DU : Dağılım türdeşliği, (\%)

qmin: Debi değerlerinin en düşük $1 / 4$ 'ünün ortalaması, $\mathrm{L} / \mathrm{h}$

$\overline{\mathrm{q}}$ : Ortalama damlatıcı debisi, L/h

Türdeşlik Katsayısı (UC, \%)

Christiansen (1942) tarafından tanımlanan ve Camp ve ark., (1997) tarafından düzenlenen türdeşlik (tekdüzelik) katsayısı, Eşitlik 2 kullanılarak hesaplanmıştır:

$\mathrm{UC}=100\left(\frac{\frac{1}{n} \sum\left|q_{\min }-\bar{q}\right|}{\bar{q}}\right)$

Eşitlikte;

$\overline{\mathrm{q}}$ : Ortalama damlatıcı debisi, $\mathrm{L} / \mathrm{h}$

qi: Damlatıcı debisi L/h

İstatistiksel Eş Dağılım (Us, \%)

Bralts ve Kesner (1983) tarafından verilen Eşitlik 4 ile hesaplanmıştır.

$\mathrm{Us}=100\left(1-C_{v}\right)=100\left(1-\frac{s_{d}}{\overline{\mathrm{q}}}\right)$

Eşitlikte;

Cv : Yapım farklılığı katsayısı

Sd : Damlatıcı debilerinin standart sapması

$\overline{\mathrm{q}}$ : Ortalama damlatıcı debisi, L/h

Sistem Su Uygulama Randımanı (Ea, \%)

Wu ve Gitlin, (1973) tarafından verilen Eşitlik 7 ile hesaplanmıştır.

$\mathrm{Ea}=\left(\frac{q_{\text {min }}}{\overline{\mathrm{q}}}\right) 100$

Ea : Sistem su uygulama randımanı (\%)

qmin : Debi değerlerinin en düşük değeri $(\mathrm{l} / \mathrm{h})$

$\bar{q}$ : Ortalama damlatıcı debisi, L/h
Alt Çeyrek Gerçek Potansiyel Uygulama Randımanı (PELQ

\%)

Meriam ve Keller, (1978) tarafından verilen Eşitlik 5 ile hesaplanmıştır

PELQ $=0.9 \times$ ERF $\times$ EU

Eşitlikte;

PELQ : Alt çeyrek gerçek uygulama randımanı (\%)

ERF : Düzeltme faktörü ( 6 no'lu eşitlikle hesaplanmaktadır).

$\mathrm{ERF}=($ Port $+1.5($ Pmin $) /(2.5$ Port $)$

Eşitlikte;

Port : Ortalama lateral giriş basıncı (atm.)

Pmin : Minimum lateral giriş basıncı (atm.)

\section{BULGULAR VE TARTIŞMA}

Lateral Debi Değişimi

Test yapılan laterallerdeki debi değişimi, her işletmede ve işletme içerisindeki manifoldlarda farklı sonuçlar vermiştir. Şekil 2'de test yapılan işletmelerin birinci manifoldlarındaki laterallerin debi değişimleri gösterilmektedir. Benzer biçimde Şekil 3'de de aynı işletmelerin iki no'lu fanifoldlarındaki laterallerin debi değişimleri gösterilmektedir. İşletmelerin bir no'lu manifold laterallerinden elde edilen sonuçlar incelendiğinde (Şekil 2) en düşük ortalama lateral debisi 13 no'lu işletmede $0.60 \mathrm{l} / \mathrm{h}$ olarak ölçülürken en yüksek ortalama lateral debisi 8 no'lu işletmede $3.80 \mathrm{l} / \mathrm{h}$ olarak ölçülmüştür. iki no'lu manifoldlarda ise en düşük ortalama lateral debisi 11 no'lu işletmede $0.66 \mathrm{I} / \mathrm{h}$ ölçülürken, 8 no'lu işletmede $3.54 \mathrm{l} / \mathrm{h}$ ile en yüksek ortalama lateral debisi ölçülmüştür. Bu denli farklılıkların çıkmasının en önemli nedeni işletmelerin kullandıkları damla sulama borularının debilerinin farklı

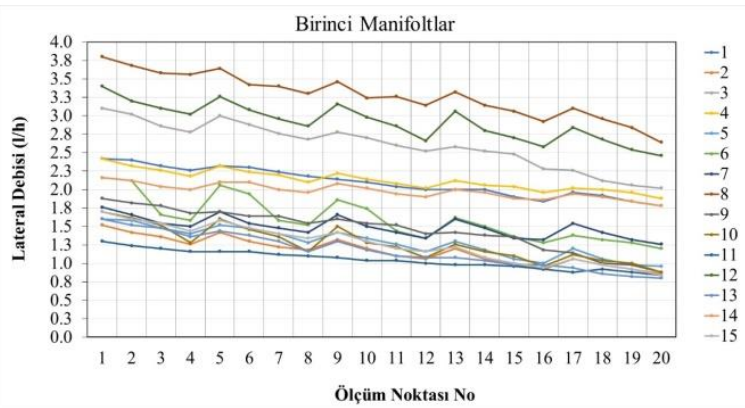

Şekil 2 İşletmelerin bir no'lu manifold laterallerindeki debi değişimleri

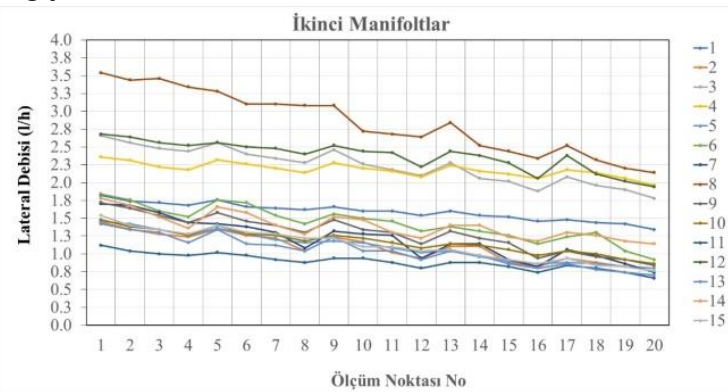

Şekil 3. İşletmelerin iki no'lu manifold laterallerindeki debi değişimleri 
olmasıdır. Şekil 2 ve 3 incelendiğinde işletmenin laterallerindeki ortalama debi değerlerinde ciddi değişimler görülmektedir. Bir no'lu laterallerdeki debi değişimi \%18 (14 no'lu işletme) ile \%53 (9 no'lu işletme) arasında değişim göstermiştir. Benzer şekilde iki no'lu manifoldların laterallerin debi değişimleri \%17 (4 no'lu işletme) ile \%70 (6 no'lu işletme) arasında değişim göstermiştir. Bu durumun en önemli nedeni, başta planlama, projeleme ve işletme koşulları olmak üzere diğer (damlatıcı tıkanıklıklar, işletme basınç yetersizliği, sistem debisinin yetersizliği gibi) faktörler olarak değerlendirilmiştir.

Ortalama akış oranı (0.89-3.27 l/h), minimum akış oranı (0.66-2.64 I/h), maksimum akış oranı $(1.12-3.80 \mathrm{l} / \mathrm{h})$ ve en düşük alt çeyrek debi ortalaması $(0.75-2.88 \mathrm{l} / \mathrm{h})$ değerlerindeki değişim ise Şekil 4'de gösterilmiştir. Söz konusu parametreler başta işletmelerin damlatıcı debilerindeki farklılıklar, işletme basınçlarındaki yetersizlik, sistem debi yetersizliği ve damlatıcı tıkanıklıklar olmak üzere diğer birçok faktör tarafından etkilenmekte ve bu nedenle de işletmeler arasında ciddi farklılıkların ortaya çıkmasına neden olmaktadır. Çalışmadan elde edilen sonuçlar benzer koşullarda Uygan ve Çetin (2015) tarafından Eskişehir ve Sakarya bölgelerindeki damla sulama sistemlerinde yapılan çalışma ile uyum içerisindedir.

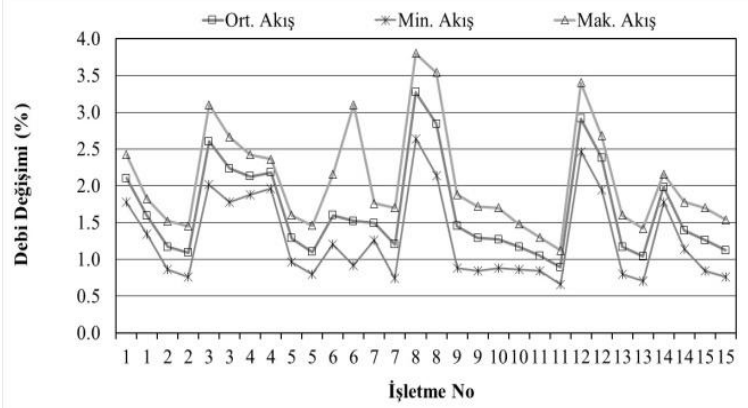

Şekil 4. İşletmelerin Ortalama akış oranı, minimum akış oranı, maksimum akış oranı ve en düşük alt çeyrek debi ortalamalarındaki değişim

İşletme manifoldlarının da ölçülen ortalama damlatıcı debilerinin farkları Şekil 5'de gösterilmiştir. Genel olarak değerlendirildiğinde 1 (\%28), 7 (\%22), 12 (\%20) ve 14 (\%35) no'lu işletmelerin manifoldlarının ortalama damlatıcı debileri arasındaki fark \%20'nin üzerinde olduğu saptanmıştır. Diğer işletmelerinki ise söz konusu değerin altında olarak belirlenmiştir. En az fark 4 no'lu işletmelerde $\% 2$ olarak belirlenmiştir. Onu 6 no'lu işletme \%5 farkla takip etmiştir. Manifolt ortalama damlatıcı debilerinin arasındaki farkın en önemli nedeni, başta işletme basınçları ve sistem debi yetersizlikler olmak üzere, damlatıcıların tıkanması, proje ve işletme hatalarından kaynaklandığı düşünülmektedir.

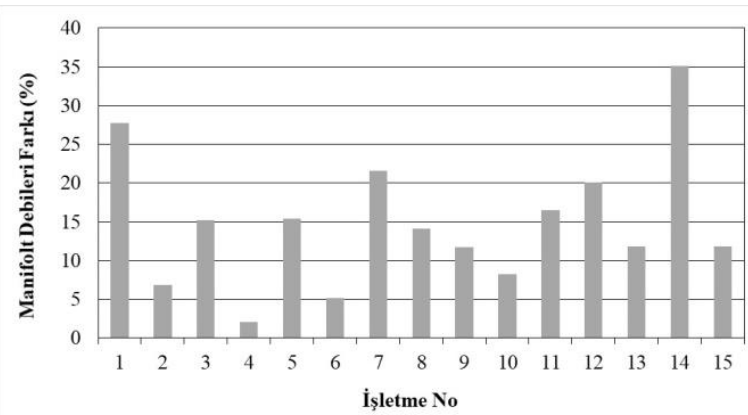

Şekil 5. İşletmelerin ortalama manifold debileri arasındaki farklar

\section{Damlatıcı Debi Türdeşliği (EU)}

EU değeri damla sulama sistemlerinde hayati öneme sahip performans göstergelerinden bir tanesidir. Doğru şekilde projelenmiş, uygulanıp ve işletildiği koşullarda bu değerin $\% 90$ ve üzerinde (mükemmel) olması beklenir. Yapılan testlerde hiçbir işletmede EU değeri mükemmel sınıfa girmemiştir. Şekil 6'dan da görüleceği üzere işletmelerin EU değerleri \%60-89 arasında değişim göstermiştir. İyi sınıfta 4 adet $(1,4,12$ ve 14 no'lu) işletme, makul sınıfta 3 adet (3, 5 ve 11 no'lu) işletme ve zayıf sınıfta ise 3 adet $(9,13$ ve 15 no'lu) işletme yer almıştır. Geriye kalan 5 işletmede ise manifoldun birisi iyi diğeri zayıf (7 no'lu işletme), birisi iyi diğeri makul (2 ve 8 no'lu işletme) ve birisi makul diğeri zayıf (2, 6 ve 10 no'lu işletme) olarak belirlenmiştir. Genel olarak değerlendirildiğinde Şekil 7'den de görülebileceği gibi, test yapılan manifoldların \%34'ü iyi sınıfta, \%33’ü makul ve \%33'ü ise zayıf sınıfta yer almıştır.

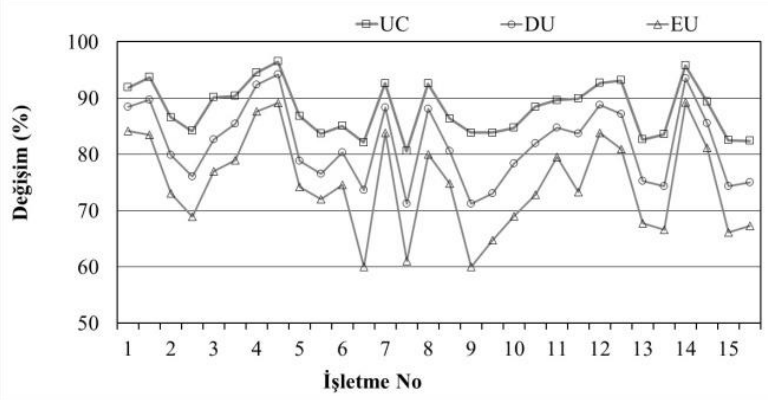

Şekil 6. Manifold damlatıcı debi türdeşliği, dağılım türdeşliği ve türdeşlik katsayısı değerleri

EU Sinıfı (\%)

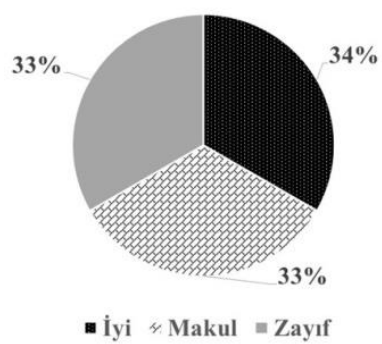

Şekil 7. Damlatıcı debi türdeşliği sınıflarının dağılımı (\%) 
Kanber ve ark. (1996)'a göre eğimi \%2'nin altında olan arazilerdeki damla sulama sistemlerinde damlatıcı debilerinin türdeşliği \%80-90, Merriam ve Keller (1978)'e ve ASAE (2003)'e göre ise, \%80'in üzerinde olması gerektiği bildirilmektedir. Yapılan çalışmada 10 tane manifoldda EU değeri \%80 -89 aralığında, 10 tane işletmeninki \%70-79 aralığında ve geriye kalan 10 tane işletmeninki ise \%60-69 aralığındadır. Diğer bir ifadeyle test edilen manifoldlardan sadece 10 tanesi iyi sınıfta yer alabilmiştir. Little ve ark. (1993) 258 adet bahçede yaptıkları çalışmada zayıf ya da yetersiz damlatıcı debi türdeşliğine, uygun olmayan sistem planlaması veya sistem unsurlarının doğru şekilde kurulmaması nedeniyle basınç değişiminin sebep olduğu belirtilmiştir. Burt (2004) su dağılım türdeşliğinin laterallerdeki basınç farkına, laterallerin yıpranması ve tıkanmasına, üretici varyasyon katsayısına ve drenaj koşullarındaki yetersizliklere bağlı olarak değiştiğini belirtmiştir. Söğüt ve Yazar (1986), Çukurova Üniversitesi Ziraat Fakültesi bünyesinde bulunan narenciye bahçesinde yaptıkları çalışmada damlatıcı debi türdeşliğini \%84 olarak tespit etmişlerdir. Ayrıca, çalışmadan elde edilen EU değerleri, Alaç (2006)'ın Adana ili Yüreğir ilçesindeki sırta dikim yapılmış narenciye bahçesindeki damla sulama sistemlerinde yapmış olduğu çalışma ile Uygan ve Çetin'in (2015) Eskişehir ve Sakarya illerindeki 13 adet işletmedeki kurulu bulunan damla sulama sisteminin performansını değerlendirmek için yapmış olduğu çalışmalarla benzerlik göstermektedir.

\section{Dağılım Türdeşliği (DU)}

Damla sulama sistemlerinin diğer bir performans göstergesi ise dağılım türdeşliğidir. Test yapılan işletmelerin DU değerleri \%71-94 arasında değişim göstermiştir (Şekil 6). DU değerleri EU değerlerinde olduğu gibi işletmeden işletmeye farklılık göstermiş ve benzer bir değişim sergilemiştir. Şekil 5 incelendiğinde, en düşük ìki manifoldun birlikte değerlendirildiği durumda, DU değeri bakımından en iyi değerler 4 no'lu işletmede \%92- 94 arasında değişirken, en düşük ise 9 no'lu işletmede \%72-73 arasında değişim göstermiştir. Su dağılım türdeşliğinin laterallerdeki basınç farkına, laterallerin yıpranması ve tıkanmasına, üretici varyasyon katsayısına ve drenaj koşullarındaki yetersizliklere (Burt, 2004); kırılmış ve yıpranmış dağıtım borularının kullanılmasının, damlatıcıların fiziksel, biyolojik ve kimyasal maddeler tarafından tıkanmasının, vanalarda tahribatlar, sistemde oluşan paslanmalar ve yanlış planlamalar etkili olabilmektedir (Goyal, 2007; Capra ve Scicolone, 1998). Çalışmadan elde edilen DU değerleri, Alaç (2006)'ın Adana ili Yüreğir ilçesindeki sırta dikim yapılmış narenciye bahçesindeki damla sulama sistemlerinde yapmış olduğu çalışma ile Uygan ve Çetin (2015)'in Eskişehir ve Sakarya illerindeki 13 adet işletmedeki kurulu bulunan damla sulama sisteminin performansını değerlendirmek için yapmış olduğu çalışmalarla benzerlik göstermektedir.

\section{Türdeşlik Katsayısı (UC)}

Damla sulama sistemlerinde dikkate alınan performans göstergelerinden bir tanesi de türdeşlik katsayısıdır. Test yapılan işletmelerin UC değerleri \% 81-97 arasında değişim göstermiştir (Şekil 6). UC değerleri EU ve DU değerlerinde olduğu gibi işletmeden işletmeye farklılık göstermiş ve söz konusu performans parametreleri ile benzer bir değişim sergilemiştir. İki manifoldun birlikte değerlendirildiği durumda, UC değeri bakımından en iyi değerler 4 no'lu işletmede \%95-97 arasında değişirken, en düşük ise 15 no'lu işletmede \%82-83 arasında değişim göstermiştir. Benzer sonuçlar Safi ve ark. (2007) 150 kPa basınç altında yapmış oldukları testte, UC değerini \%85.1-93.7 arasında belirlemişlerdir. Elde edilen sonuçlarla karşılaştırıldığında genel olarak bir uyumluluk söz konusudur.

\section{İstatistiksel Eş Dağılım (Us)}

Çalışma yapılan manifoldlara ait istatistiksel eş dağılım değerleri Şekil 8'de sunulmuştur. Us değerleri \%68-96 arasında değiştiği tespit edilmiştir. 15 no'lu işletmeye ait olan iki no'lu manifoldda istatistiksel eş dağılımı \%68 olarak belirlenmiş ve $\% 70$ 'in altında olmasından dolayı zayıf olarak sınıflandırılmıştır. Ancak, burada göz önünde bulundurulması gereken önemli husus ise bölgedeki işletmelere su sağlayan sulama şebekesinin oldukça geniş bir bölgeye hizmet vermesi ve dolayısıyla da aynı anda birçok işletmenin şebekeden su almasına bağlı olarak, işletmelerin sulama performansında düşüş yaşanmaktadır. 15 no'lu işletmedeki testin yapıldığı zaman diliminin böyle bir ana denk geldiği düşünülmektedir.

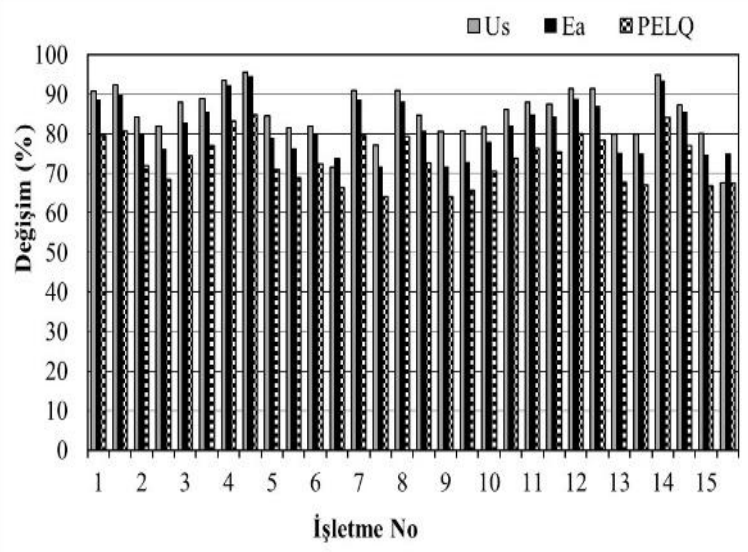

Şekil 8. Sistem Su Uygulama Randımanı (Ea, \%), Alt Çeyrekte Potansiyel Uygulama Randımanı (PELQ, \%) ve Akış Değişimi (\%) değerleri

Şekil 9 incelendiğinde, manifoldların istatistiksel eş dağılım bakımından \%31'i mükemmel, \%55'i çok iyi, \%10'u makul ve \%4'ü zayıf sınıfta yer almıştır. Elde edilen istatistiksel eş dağılım sonuçları, Bozkurt (1996)'un 12 adet in-line damlatıcıda yaptığı çalışmada bir damlatıcı hariç, diğerlerinde istatistiksel eş dağılımı \%95'in üzerinde bulmasıyla uyumludur. 


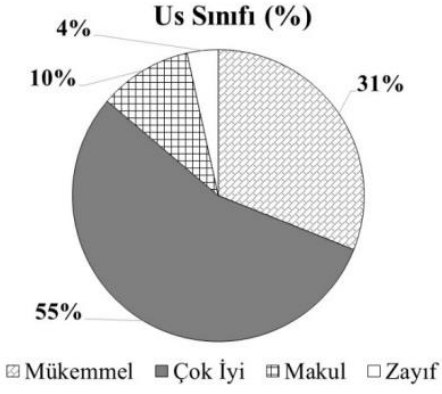

Şekil 9. İstatistiksel eş dağılım sınıflandırması

\section{Sistem Su Uygulama Randımanı (Ea)}

Damla sulama sisteminde, normal şartlarda kayıp-kaçak oranı düşük olduğundan, Ea, \%85-95 arasında değişmektedir. Çalışmanın yapıldığı 11 işletmede su uygulama randımanı \%85'lik alt değerin altında kalmıştır. Sulama randımanın (Ea) düşük olduğu bu işletmelerde bitkilerin, verilen sudan yeterince yararlanamadığı değerlendirilmektedir. Düşük damlatıcı debi türdeşliği (EU) ve su uygulama randımanına (Ea), sistemdeki su sızıntıları, yetersiz filtreleme, deforme olan sistem parçaları sebep olabilir (Dalvi ve ark., 1995).

\section{Alt Çeyrekte Potansiyel Uygulama Randımanı (PELQ)}

PELQ değeri, işletmede optimum su uygunluğunu, sistemin ne denli iyi performans gösterdiğinin ya da sistem tasarımının ne denli uygun olduğunu gösteren bir ölçüdür (Bhavan ve Maro, 1991). Test edilen damla sulama sistemlerinin, alt çeyrekte potansiyel uygulama randımanları, \%64-85 arasında değişim göstermiştir (Şekil 8). Merriam ve Keller (1978)' in damla sulama için belirttiği PELQ sınır değeri \%75-90 olup söz konusu değer, uygunluk sınırı değerleri olarak kabul edilmektedir. Test yapılan toplam 30 manifoldun 17'sinde hesaplanan PELQ değeri $\% 75^{\prime}$ in altında ve geri kalan 13 işletmede bu sınır değerin üzerinde olduğu belirlenmiştir. Sadece 4 no'lu işletmenin her iki manifoldu ve 14 no'lu işletmenin birinci manifoldunda PELQ değeri \%80'nin üzerinde saptanmıştır. Düşük PELQ sistemde tasarım sorunlarının olduğunun işaretidir. Yapılan gözlemlerde ise, çiftçilerin damla sulama sistemlerini mevcut toprak ve bitki özelliklerine göre projeleme yapmadıkları tespit edilmiştir. Bu durum ise sistemlerin hidrolik yönden de uygun bir projeleme yapılmadığını da göstermektedir. Test yapılan işletmelerde yapılan görüşmelerde, damla sulama sistemi projelendirme ve uygulama aşamasında, konu uzmanı olmayan kişilerce gerçekleştirildiği belirlenmiştir. Çalışmadan elde edilen sonuçlar Uygan ve Çetin (2015)'in Eskişehir ve Sakarya illerini kapsayan ve 13 adet işletmede yapmış oldukları test sonuçları ile benzerlik göstermektedir.

\section{SONUÇ}

Suyunun kalitesi, damlatıcıların debilerini etkileyen önemli bir faktördür. Özellikle mineral içeriği yüksek ve iyi filtrelenmemiş sular, kısa zamanda damlatıcılarda tıkanmalara sebep olmakta ve damlatıcının verimini düşürmektedir. Çalışmanın yürütüldüğü işletmelerin damla sulama sistemlerinde kimyasal yıkama yapılmadığından dolayı, mineral tuzlarının birikmesi sonucu tıkanan damlatıcıların performansı zamanla azalacaktır. Tıkanan damlatıcılar on-line oldukları takdirde sökülüp değiştirilebilirken, in-line damlatıcılar için böyle bir seçenek söz konusu değildir. In-line damlatıcıların tıkanıklıklarını gidermek ancak sisteme asit uygulanması ile mümkün olabilmektedir. Ancak üreticiler damla sulama konusundan yeterli bilgiye sahip olmamalarından dolayı, sistemle uygulanacak gübre ve diğer uygulamaların hem sulama sistemine hem de bitkiye zarar vereceğini düşünmekteler. Testler sırasında yapılan görüşmelerde, işletmelerin büyük bölümünün damla sulama sisteminin alımında herhangi bir mühendislik hizmeti alınmadan tamamen gelişigüzel tasarlanıp kurulduğu, ayrıca sistemi kuran firmaların kendi maddi çıkarları için, sistemin performansını da hiçe sayıp, gereksiz malzeme kullanarak maliyetleri arttırdığı tespit edilmiştir. Ayrıca, işletmelerin sistemi kurulmadan önce hiçbirinde toprak bünye analizi, infiltrasyon testi ve sulama suyu analizinin yaptırılmadığı belirlenmiştir.

Elde edilen sonuçlar ve tespitler dikkate alındığında Bursa bölgesinde kullanılmakta olunana damla sulama sistemlerinde ciddi problemlerin olduğu söylenebilir. Gelecekte, kurulacak sistemlerin mutlak konu uzmanlarınca gerekli çalışmaları yapılarak projelendirilmesi, tesis edilmesi ve işletilmesinin sağlanması gerekmektedir. Ayrıca, mevcut sistemlerin de gerekli kontrollerden geçirilerek uygun düzenlemelerle ve işletme yöntemleriyle ekonomik ömürlerini tamamlayana kadar kullanılması gerekmektedir.

\section{KAYNAKLAR}

Alaç V (2006) Sırta Dikim Yapılmış Narenciye Bahçelerinde Kurulu Bulunan Damla Sulama Sistemlerinin Performansının Değerlendirilmesi. Yüksek Lisans Tezi. Çukurova Üniversitesi, Adana.

ASAE (2003) Design and Installation of Microirrigation Systems. ASAE EP405.1 Dec.01, p.903-907.

Bhavan M, Maro BSZ (1991) Irrigation Equipment and Systems, Evaluation of Field İrigation Efficienciens, Guidelines. New Delhi, India, I 10002.

Bozkurt S (1996) İçten Geçik (in-line) Damlatıcılarda Yapım Farklılıklarının Eş Su Dağılımına Etkileri. Yüksek Lisans Tezi. Çukurova Üniversitesi, Adana.

Bralts VE, Kesner CD (1983) Drip irrigation field uniformity estimation. Transactions of the ASAE. American Society of Agricultural Engineers. (26)5: 1369-1374.

Burt CM (2004) Rapitfield evaluation of drip and micro spray distribution uniformity. Irrigationand Drainage Systems, 18: 275-297.

Camp CR, Sadler EJ, Busscher WJ (1997) Acomparison Of Uniformity Measures For Drip Irrigation Systems. Trans. ASAE, 40 (4):1013-1020. 
Capra A, Scicolone B (1998) Water Quality And Distribution uniformity In Drip/Trickle Irrigation systems, J. Agric. Eng. Res., 70: 355-365.

Dalvi VB, Satpute GU, Pawade MN, Tiwari KN (1995) Growers' experiences and on farm microirrigation efficiencies. 1. Microirrigation Congress. F.R. Lamm (Ed.), ASAE, St. Joseph, Michigan. Pp. 775-780.

Goyal MR (2007) Management of Drip/Micro or Trickle Irrigation, Chapter XV, Agricultural And Biomedical Engineering, Universty of Puerto Rico-Mayo Güez Campus, P.O Box 5984, Nayagüez-PR-00681-5984.

Kanber R, Öğretir K, Güngör H, Kara C (1996) Sulanır Alanlarda Su Kullanım Etkinliğinin (Randıman) Değerlendirilmesi. Köy Hizmetleri Araştırma Ana Projesi. Proje No: 423, Eskişehir, $116 \mathrm{s.}$

Keller I, Karmeli D (1975) Trickle Irrigation Desing. Glendora, U.S.A., Rain Bird Sprinks Mfg.Corporation.

Lamm FR, Storlie CA, Pitts JP (1997) Field Evaluation of Microirrigation Systems. ASAE Arinual International Meeting Minneapolis, (August 10-14), 972070 p, Minnesota.

Little GE, Hills DJ, Hanson BR (1993) Unifomity in Pressurized Irragation Systems Depends on Desing Installation. California Agriculture, 47 (3): 18-21.

Merriam JL, Keller J (1978) Farm irrigation evaluation: A guide for management. Department of Agricultural and İrrigation Engineering, Utah State University, Logan, Utah.
DAVARCI B, TAŞ i

Mohammed MZMM (2018) Konya-Akşehir İlçesindeki Kiraz Bahçelerinin Sulanmasında Kullanılan Damla Sulama Yönteminin Değerlendirilmesi. Yüksek Lisans Tezi. Selçuk Üniversitesi, Konya.

Orta AH (1991) Antalya Yöresindeki Damla Sulama Uygulamalarında Karşılaşılan Sorunlar ve Çözüm Yolları. Yüksek Lisans Tezi. Ankara Üniversitesi, Ankara.

Safi B, Neyshabourı MR, Nazemı AH, Massıha S, Mırlatıfı SM (2007) Water Application Uniformity of a Subsurface Drip Irrigation System at Various Operating Pressures and Tape Lengths. Turk J Agric For 31: 275-285.

Söğüt A, Yazar A (1986) Meyve Bahçelerinin Sulanmasında Kullanılan Damla Sulama Sistemlerinin Değerlendirilmesi. Çukurova Üniversitesi. Fen Bilimleri Enstitüsü Dergisi 1: 62

Uygan D, Çetin Ö (2015) Eskişehir ve Sakarya illeri'nde Kurulu Bazı Damla Sulama Sistemlerinde Performans Göstergelerinin Değerlendirilmesi. Toprak Su Dergisi, 4(1):27-35.

Wu IP, Gitlin HM (1973) Hydraulics and Uniformity for Drip Irrigation. Journal of the Irrigation and Drainage Division (ASCE), 99:2, p.157-168

Yazgan S, Değirmenci H, Büyükcangaz H, Demirtaş Ç (2000) Bursa Yöresi Zeytin Yetiştiriciliğinde Sulama Sorunları, Zeytin Sempozyumu, 6-9 Haziran 200, Bursa, s. 275282. 
